\title{
Determinants of institutional delivery service utilization among pastorals of Liben Zone, Somali Regional State, Ethiopia, 2015
}

This article was published in the following Dove Press journal:

International Journal of Women's Health

9 December 2016

Number of times this article has been viewed

\author{
Nejimu Biza Zepro' \\ Ahmed Tahir Ahmed ${ }^{2}$ \\ 'College of Health Sciences, Samara \\ University, Samara, Afar, Ethiopia; \\ ${ }^{2}$ College of Health Science, Jigjiga \\ University, Jigjiga, Somali, Ethiopia
}

Correspondence: Nejimu Biza Zepro College of Health Sciences, Samara University, PO Box 132, Samara,

Afar Region, Ethiopia

Tel +25l 9 I004 682I

Email nejim76@gmail.com
Abstract: Maternal health service utilizations are poorly equipped, inaccessible, negligible, and not well documented in the pastoral society. This research describes a quantitative and qualitative study on the determinants of institutional delivery among pastoralists of Liben Zone with special emphasis on Filtu and Deka Suftu woredas of Somali Region, Ethiopia. The study was funded by the project "Fostering health care for refugees and pastoral communities in Somali Region, Ethiopia". This community-based cross-sectional study was conducted during November 2015. Interviews through a questionnaire and focus group discussions were used to collect the data. Proportional to size allocation followed by systematic sampling technique was used to identify the study units. The major determinants of institutional delivery in the study area were as follows: being apparently healthy, lack of knowledge, long waiting time, poor quality services, cultural beliefs, religious misconception, partner decision, and long travel. Around one-third (133, 34.5\%) of the women had visited at least once for their pregnancy. More than half $(78,58.6 \%)$ of the women had visited health facilities due to health problems and only 27 (19.9\%) women had attended the recommended four antenatal care visits. Majority $(268,69.6 \%)$ of the pregnant women preferred to give birth at home. Women who attended antenatal care were two times more likely to deliver at health facilities (AOR, 95\% confidence interval $[\mathrm{CI}]=2.38,1.065-4.96)$. Women whose family members preferred health facilities had 14 times more probability to give birth in health institutions (AOR, 95\% CI =13.79, 5.28-35.8). Women living in proximity to a health facility were 13 times more likely to give birth at health facilities than women living far away (AOR, $95 \%$ CI $=13.37,5.9-29.85$ ). Nomadic way of life, service inaccessibility, and sociodemographic and cultural obstacles have an effect on the utilization of delivery services. Increasing access, information, education, and communication need to reach pastoral women in need.

Keywords: pastoralism, delivery service utilization, Liben Zone, Somali Region, Ethiopia

\section{Background}

Maternal mortality ratio in Ethiopia was 676 deaths per 100,000 live births in 2011. Approximately seven (6.76\%) women died within 2 months of delivery and childbirth. The neonatal mortality rate was 37 deaths per 1,000 live births. Moreover, it has been reported that approximately six in every 10 Ethiopian women (57\%) did not receive any antenatal care (ANC) for their last birth in the 5 years preceding the survey. ${ }^{1}$

Institutional delivery service, an important component in efforts to reduce health risks to mothers and their children, helps in increasing the proportion of babies that are delivered in health facilities. It is an effective intervention for reducing the risk of maternal morbidity and mortality, especially in places where the general health status of women is poor. ${ }^{2}$ 
Skilled delivery service use in pastoral communities is very low. There are high variations in institutional delivery service utilizations among regions of Ethiopia, with $<10 \%$ in Southern Nations Nationalities, Afar, Oromiya, Somali, and Benishangul-Gumuz regions and up to $82 \%$ in Addis Ababa. Antenatal care from a skilled provider ranges from $15 \%$ in the Somali Region up to $94 \%$ in Addis Ababa. The wide discrepancy between country and region informs concerned stakeholders that there is a long way to go for bridging maternal health service utilization gap between agrarian and pastoral communities for the country in general and the Somali Region in particular., ${ }^{2,3}$

In Ethiopia, the estimated maternal mortality rate was $673 / 100,000$ live births in 2005, but the trend does not show an improvement when compared to 676/100,000 live births in 2011. Improvements have been made in the proportion of pregnant women using ANC, with $28 \%$ in $2005,37 \%$ in 2011 , and $40 \%$ in 2014. The proportions of births attended by skilled health personnel were $6 \%$ in $2005,10 \%$ in 2011 , and $15 \%$ in 2014. The proportion of births delivered in a health facility ranges from $10 \%$ in Somalia to $87 \%$ in Addis Ababa. ${ }^{4}$

Reproductive, maternal, newborn, child, and adolescent health (RMNCAH) will continue to be top priority for the next 5 years. As indicated in the sustainable development goals, Ethiopia will intensify interventions to end preventable maternal and child deaths by 2030.5

Institutional delivery service utilization is underutilized in Somali Region due to different constraints and obstacles. Hence, understanding the determinants and constraints of institutional delivery service utilization in the pastoral area is very crucial for proper use of the maternal health service, which is one of the most effective strategies for preventing maternal mortality. Undertaking research on the determinants of institutional delivery provides evidence for the improvement of maternal health care strategies in places where the general health status of women is very low. ${ }^{3}$

This study identified the determinants and constraints of institutional delivery in the Liben Zone in general, and Filtu and Deka Suftu woredas in particular. Effective implementation should be done to avoid the negative causes and constraints of institutional delivery within the society.

Findings of this study will give insight for policy makers and implementing organizations for setting strategies to encourage institutional delivery in pastoral areas.

\section{Study area}

The study was carried out in the Liben Zone, particularly in Filtu and Deka Suftu woredas. The zone has six woredas, of which two are newly established. The woredas border the Dawa River on the south, the Oromia Region on the west, and the Ganale River on the north and east.

Based on the Ethiopian census, with the national average annual growth rate of $2.6 \%$, the total population of these two woredas is 152,803 , of whom 87,098 are men and 65,705 are women, ${ }^{6}$ and 5,455 (3.57\%), 107,359 (70.26\%), and 39,989 (26.17\%) of the population are urban inhabitants, pastoralists, and agropastoralists, respectively. In addition, $99 \%$ of the population is Muslim by religion.

In the Filtu woreda, there is one hospital, two health centers, and 22 health posts, while Deka Suftu has one health center and nine health posts. During the preliminary survey, the data registry showed only 180 deliveries in Filtu hospital by the year 2014, while 298 deliveries were recorded in 2015 (Filtu woreda health office).

\section{Methods}

A cross-sectional community-based quantitative and qualitative study design was used to assess the determinants of institutional delivery in Liben Zone, Somali Region, eastern Ethiopia.

\section{Study population}

All women of reproductive age (15-49 years) residing in Filtu and Deka Suftu districts were the source population, and pregnant women residing in Filtu and Deka Suftu districts as permanent residents were selected as the study population.

\section{Sample size determination}

The sample size was determined using the single population proportion formula $n=\frac{Z_{(\alpha / 2)}^{2} p(1-p)}{w^{2}}$, where $n$ is the sample size, $\mathrm{z}$ is the standard normal deviation, set at 1.96 (for $95 \%$ confidence interval [CI]), $w$ is the desired degree of accuracy (taken as 0.05 ) and $p$ is the estimate prevalence of institutional delivery (50\%), and the required total sample size was 385 women.

\section{Sampling procedure}

Multistage sampling method was used for the Liben Zone, which consists of six woredas. Two woredas were selected by purposive sampling technique. The calculated sample sizes (385) were proportionally allocated to each selected woreda based on its size of households. A systematic sampling technique was then used to identify the study households.

In the event where there was no pregnant woman in the selected household, the next household was visited. Moreover, in cases where the selected household was closed 
or the eligible person was absent, two attempts were made to find the respondents.

\section{Data collection method}

Data were collected by 15 female data collectors who were familiar with the study area and local language. A standardized structured questionnaire was developed after serious revision and investigation of existing relevant studies. The original English version of the questionnaire was translated into local language (Somali version), and then the local version was translated back into English by professionals to check its consistency. Interviewer-administered exit interview was conducted in a private and quiet room for audio privacy. Supervisors and the principal investigator monitored data collection very closely. The questionnaire was pretested in $10 \%$ of the sample size in other kebeles before the actual study and appropriate modifications were made accordingly.

Highly structured four focus group discussions (FGDs) (Filtu, Malkahagar [Baladulamin], Ayinle, and Deka Suftu) were used to collect relevant data from the informants. The FGD participants were composed of different groups such as women in childbearing age, health professionals working in health institutions, traditional birth attendants, community leaders, clan leaders, religious leaders, and woreda or kebele officials in the study areas. Four FGDs were conducted in both woredas, and the participants were drawn from different groups as mentioned earlier. There were 31 group discussants and the maximum number of participants in each group were 6-8 in order to make it manageable in size.

\section{Data quality control}

The questionnaire was pretested a week before the actual data collection time on a sampled unit in a kebele, which was not selected for the actual study, and modification was done accordingly.

Data collectors and supervisors were trained by the principal investigator. During data collection, trained supervisors strictly supervised the correctness of the questionnaire and the procedure every day. The principal investigator also checked the completeness and correctness of the filled questionnaire. Data were entered using the EpiData software, version 3.02. Finally, data were cleaned before the actual analysis.

\section{Data processing and analysis}

The collected data were entered into a computer using the EpiData software; the data were cleaned and then exported to SPSS software, version 20 (IBM Corporation, Armonk, NY,
USA) for further analysis. The frequencies and percentages were calculated for all variables that were related to the objectives of the study.

Odds ratio (OR) with $95 \% \mathrm{CI}$ was used to examine the associations between dependent and independent variables. To confirm the association, variables found to have a strong association in the bivariate analysis were transferred to a final multivariate model. Moreover, multivariate logistic regression analysis was done to control confounders and study the separate effects of the various factors associated with the intentions of pregnant women about the place of delivery. For multivariable analysis, statistical significance was considered when $P$-value was $<0.05$.

\section{Ethical considerations}

The study obtained ethical clearance from the zonal and woreda administration, as well as from the woreda Health Bureau and Filtu Hospital Administration. A formal letter was submitted to all concerned bodies in the region to obtain their cooperation in facilitating the study.

All interviews were conducted after obtaining a written signed informed consent from the respondents. Data were then collected by respecting the rights of the respondents by making the information provided by the respondents anonymous.

\section{Results}

\section{Sociodemographic and economic characteristics of the mothers}

A total of $385(100 \%)$ responses were obtained from the sample population. Both the mean and median age were 30 years, with a standard deviation of 7.5 years. Almost all study participants were Somali by ethnicity and Muslim by religion.

Regarding educational background, more than half of the women and their husbands were preliterate. With regard to occupation, majority of the women $(305,79.2 \%)$ were homemakers, while the remaining were either private employees or government employees. Most of the study participants have income categories (200-1,000 ETB and 1,001-3,000 ETB) (Table 1).

\section{Antenatal care service utilization}

The majority $(330,85.7 \%)$ of the pregnant women had not yet faced any obstetric problems, while the remaining had faced at least one problem, such as vaginal bleeding, headache, severe abdominal pain, and drowsiness. Approximately one-third $(133,34.5 \%)$ of the women had visited health facilities during pregnancy at least once. 
Table I Sociodemographic characteristics of respondents in Liben Zone, Somali Region, 2015

\begin{tabular}{lll}
\hline Factors & Frequency & Percentage \\
\hline Maternal age (years) & & \\
I5-19 & 28 & 7.3 \\
$20-24$ & 66 & 17.1 \\
$25-29$ & 91 & 23.6 \\
$30-34$ & 90 & 23.4 \\
$35-39$ & 51 & 13.2 \\
40-45 & 59 & 15.3 \\
Women's education & & \\
Preliterate & 233 & 60.5 \\
Read and write & 94 & 24.4 \\
Primary level & 34 & 8.8 \\
Secondary and above & 24 & 6.2 \\
Women's occupation & & \\
Housewife & 305 & 79.2 \\
Government employee & 44 & 11.4 \\
Private employee & 36 & 9.4 \\
Husband's occupation & & \\
Not employed & 177 & 46.0 \\
Employed & 208 & 54.0 \\
Husband's education & & \\
Preliterate & 220 & 57.1 \\
Read and write & 94 & 24.4 \\
Primary level & 36 & 9.4 \\
Secondary and above & 35 & 9.1 \\
Monthly household income (ETB) & & \\
200-I,000 & 205 & \\
I,00I-3,000 & 162 & \\
$\geq 3,00 I$ & 18 & \\
\hline & & \\
\hline
\end{tabular}

Among visitors to the health facilities, more than half (78, $58.6 \%$ ) of them had visited the health facilities due to health problems related to their pregnancies, while the remaining had visited because of other health problems and for ANC follow-up. Among all ANC attendants, only a few (27, 19.9\%) women had attended the recommended four ANC contacts (Table 2).

\section{Delivery place preference}

Regarding the women's knowledge about pregnancy and delivery-related services, $168(43.6 \%)$ of the pregnant women had good knowledge, while the remaining had poor knowledge. Regarding the women's attitude toward institutional delivery services, $232(60.3 \%)$ of them had favorable attitudes and the remaining had unfavorable attitudes. One participant from the rural area said

Some women do not want to go to health institutions for fear of being seen by male physician. The religion does not allow male physician to see the private part of a women except his wife and close relative that he can't marry them.
Table 2 Distribution of obstetric characteristics of respondents in Liben Zone, 2015

\begin{tabular}{lll}
\hline Factors & Frequency & Percentage \\
\hline $\begin{array}{l}\text { Problem in current pregnancy } \\
\text { Yes }\end{array}$ & 55 & 14.3 \\
No & 330 & 85.7 \\
Visit to HF on current pregnancy & & \\
Yes & 133 & 34.5 \\
No & 252 & 65.5 \\
Reason for visit to HF & & \\
Pregnancy-related problem & 78 & 58.6 \\
Other health problems & 47 & 35.3 \\
For ANC & 8 & 6.0 \\
ANC follow-up & & \\
Yes & 136 & 35.3 \\
No & 249 & 64.7 \\
Number of ANC visits & & \\
One & 44 & 32.4 \\
Two & 45 & 33.1 \\
Three & 20 & 14.7 \\
Four & 27 & 19.9 \\
\hline
\end{tabular}

Abbreviations: ANC, antenatal care; HF, health facility.

On the other hand, one discussant who is a religious leader clarified the woman's argument as a misconception. He said,

If there is one male physician and one female physician with the same knowledge and experience, the religion prefer female physician to provide the care. But, if the male physician is knowledgeable than the female and if there is no any female physician around, then, male physician can take care of the delivery service.

There are some people who are creating misconceptions about institutional delivery. They tell pregnant women that if they deliver within health institutions, men are going to see their "private body".

With regard to their perceptions about pregnancy and childbirth complications, the majority $(299,77.7 \%)$ are receptive. In relation to availability of a nearby health facility for skilled delivery attendants (SDAs), only 35 (9.1\%) of them have proximal access to maternal health services.

Transportation problem is the major obstacle for institutional delivery and childbirth. One discussant said

If a pregnant mother is suffering nearby center of Ayinle kebele, there is no transportation even motorcycle. Relative must rent a private motorcycle with 500 birr and take the physicians to where she is suffering. This health post is the only place where people living in this Kebele and its surroundings get the service. 
Hence, one discussant said

We can say that the quality of offering effective service for pregnant women remains very low especially in the rural areas where the hospital is far from them.

According to the responses of the study participants, more than half $(255,66.2 \%)$ of the husbands prefer home delivery for their wife with the assistance of unskilled delivery attendants, and the majority $(268,69.6 \%)$ of the pregnant women prefer to give birth at home. Another FGD discussant said

The main reason for home delivery by most women is the presence of nearby relatives, being healthy, more trust on Traditional Birth Attendants (TBA). I personally feel confident when my mother and sisters are around me and assisting me in delivering.

On the other hand, another discussant said

Most women with experience in giving births more than once did not want to go to health institutions because they think that they had enough experience and don't need assistance of health workers.

Crude analysis was done by applying binary logistic regression to test the association between sociodemographic variables and women's intentions about the place of delivery. Maternal age, educational status, and occupation, as well as education and occupation of the husband, were significantly associated with the intentions of pregnant women about the place of delivery $(P<0.05)$. On the other hand, some of the discussants argued that the health institutions have the capacity to serve delivery. However, they said "It is lack of education, awareness and illiteracy that results absence from institutional delivery." Moreover, monthly household income was not significantly associated with women's intentions about the place of delivery (Table 3).

Regarding women's decision-making power in relation to getting institutional delivery, $\sim 91(23.6 \%)$ were able to make decisions by themselves, while the majority had to get this decision either from their husbands or from their relatives (Table 4 ).

\section{Determinants of place of delivery}

Age, occupation, and education level of the mother and occupation and education level of the husband, attitude, reinforcing, enabling, perceptions, and decision-making factors were included in the model. Backward stepwise method in
Table 3 Women's intentions about place of delivery in Liben Zone, Somali Region, Ethiopia, 2015

\begin{tabular}{|c|c|c|c|}
\hline Factors & HD & HF & Crude OR $(95 \% \mathrm{CI})$ \\
\hline \multicolumn{4}{|l|}{ Maternal age, years } \\
\hline $15-19$ & 24 & 4 & I \\
\hline $20-24$ & 47 & 19 & $2.426(0.74-7.9)$ \\
\hline $25-29$ & 55 & 36 & $3.927(1.26-12.3)$ \\
\hline $30-34$ & 80 & 10 & $0.75(0.21-2.6)$ \\
\hline $35-39$ & 27 & 24 & $5.33(1.6-17.6)$ \\
\hline $40-45$ & 35 & 24 & $4.11(1.3-13.4)$ \\
\hline \multicolumn{4}{|l|}{ Women's education } \\
\hline Preliterate & 193 & 40 & I \\
\hline Read and write & 46 & 48 & $5.03(2.96-8.54)$ \\
\hline Primary level & 18 & 16 & $4.28(2.02-9.12)$ \\
\hline Secondary and above & II & 13 & $5.7(2.38-13.6)$ \\
\hline \multicolumn{4}{|l|}{ Women's occupation } \\
\hline Housewife & 233 & 72 & I \\
\hline Government employee & 19 & 25 & $4.258(2.22-8.17)$ \\
\hline Private employee & 16 & 20 & 4.045 (1.99-8.21) \\
\hline \multicolumn{4}{|l|}{ Husband's occupation } \\
\hline Unemployed & 145 & 32 & \\
\hline Employed & 123 & 85 & $3.13(1.95-5.02)$ \\
\hline \multicolumn{4}{|l|}{ Husband's education } \\
\hline Preliterate & 168 & 52 & I \\
\hline Read and write & 66 & 28 & I.37 (0.79-2.3) \\
\hline Primary level & 20 & 16 & $2.59(1.2-5.3)$ \\
\hline Secondary and above & 14 & 21 & $4.85(2.3-10.2)$ \\
\hline \multicolumn{4}{|c|}{ Monthly household income (ETB) } \\
\hline $200-1,000$ & 143 & 62 & I \\
\hline $1,001-3,000$ & 114 & 48 & $0.97(0.62-1.52)$ \\
\hline$\geq 3,001$ & II & 7 & $1.47(0.54-3.96)$ \\
\hline
\end{tabular}

Abbreviations: $\mathrm{HD}$, home delivery; $\mathrm{HF}$, health facility; OR, odds ratio; $\mathrm{Cl}$, confidence interval.

multivariate logistic regression was used for adjusting the confounding factors.

Women's influences from other family members about the place of delivery showed a significant difference between women who had intended to deliver at health facilities and those who had intended to deliver at home. Women whose family members prefered health facilities are $\sim 14$ times more likely to deliver at health facilities than women whose family members preferred a home delivery (adjusted odds ratio [AOR], 95\% CI =13.76, 5.28-35.8).

Women who had nearby facilities to their residents were 13 times more likely to give birth in institutions than women who had no ability to access nearby health facilities to their residents (AOR, 95\% CI =13.38, 5.9-29.85). However, the vast majority who are poor and belong to a rural community cannot afford to pay the money for health care such as medicine, hence, they prefer to deliver at home with the help of "traditional birth agents", said one male discussant.

Some women attend antenatal care throughout the whole pregnancy period but usually they deliver at home because 
Table 4 Determinants of Institutional delivery among women in Liben Zone, 2015

\begin{tabular}{|c|c|c|c|c|}
\hline Factors & Home & HF & COR $(95 \% \mathrm{CI})$ & AOR $(95 \% \mathrm{Cl})$ \\
\hline \multicolumn{5}{|l|}{ Influence from family } \\
\hline Unfavorable & 226 & 29 & I & 1 \\
\hline Favorable & 42 & 88 & $31(17-56)$ & I3.76 (5.28-35.8) \\
\hline \multicolumn{5}{|l|}{ Ability to get nearby HFs } \\
\hline Yes & 81 & 98 & $12(6.8-20)$ & I 3.374 (5.9-29.85) \\
\hline No & 187 & 19 & 1 & 1 \\
\hline \multicolumn{5}{|l|}{ Husband's education } \\
\hline Preliterate & 168 & 52 & I & 1 \\
\hline Read and write & 66 & 28 & I.37 (0.8-2.3) & $1.40(0.616-3.19)$ \\
\hline Primary level & 20 & 16 & $2.59(1.2-5.3)$ & $5.83(2.029-16.73)$ \\
\hline Secondary and above & 14 & 21 & $4.85(2-10.2)$ & $4.16(0.874-19.74)$ \\
\hline \multicolumn{5}{|l|}{ Have ANC visit } \\
\hline Yes & & & $10.5(6.4-17.5)$ & $2.297(1.065-4.96)$ \\
\hline No & & & 1 & 1 \\
\hline
\end{tabular}

Abbreviations: ANC, antenatal care; $\mathrm{AOR}$, adjusted odds ratio; $\mathrm{Cl}$, confidence interval; $\mathrm{COR}$, crude odds ratio; $\mathrm{HF}$, health facility.

labour is unpredictable specially for rural community and arises suddenly without warning and especially if it is in the night time, due to transport problem; the women do not have much choice rather than delivering at home

he added. Moreover, the hospital can be regarded as a better place for safe delivery since an Italian non-governmental organization called Comitato Collaborazione Medica (CCM) supports the hospital with manpower, materials, medicine, and other important staff for delivering mother.

Mostly the health workers giving delivery care services in the health institution are students and do not have adequate knowledge to assist child delivery because of this fear some women rather prefer to give birth at home with the assistance of TBAs

said one elder discussant from the local community. Another female discussant stated that

If you go to health institution you will find low quality of services and lack of respect and mistreatment from some of the health care providers. Moreover, the un experienced health workers may operate the pregnant mother.

The discussants said that "health care providers will put their hands into the private part of delivering mother and she will suffer". Moreover, there is a misconception that a medicine for preventing another pregnancy will be given by health care providers. Hence, there is a widely held perception that home delivery is preferable.

Moreover, women whose husbands have primary-level education are almost six times more likely to deliver at health facilities compared to women whose husbands are preliterate (AOR, 95\% CI =5.826, 2.029-16.727).
Women's ANC attendances also became an important factor that determined a women's place of delivery. Women who attend $\mathrm{ANC}$ were two times more likely to deliver at HFs than women who did not attend ANC (AOR, 95\% CI =2.297, 1.065-4.955) (Table 4).

\section{Discussion}

Home delivery is still a norm in pastoral communities; maternal mortality tends to be higher where this is the case. In this study, $69.6 \%$ of births took place at home with the assistance of unskilled individuals, while the remaining intended to deliver at health facilities with skilled professionals. This is lower than other studies done in northwest Ethiopia where the rates of home delivery ranged between $85 \%$ and $86.2 \%{ }^{4,7}$

Only $168(43.6 \%)$ of the pregnant women had good knowledge of skilled delivery service use, while the rest had poor knowledge. Regarding their attitudes toward the utilization of institutional delivery services, $232(60.3 \%)$ had a favorable attitude toward service utilization. With regard to their perceptions about pregnancy and childbirth complications, the majority $(299,77.7 \%)$ of them were receptive.

Women's influences from other family members about the place of delivery showed a significant difference between women who intended to deliver at HFs and those who intended to deliver at home. Women whose family members preferred HFs were $\sim 14$ times more likely to deliver at HFs than women whose family members prefer home delivery (AOR, 95\% CI $=13.759,5.276-35.8$ ).

This study also indicates that there is a significant association between women's intentions about their place of delivery and their ability to get HFs with SDA nearby to 
their residents. Therefore, women who have HFs with SDA nearto their residents are 13 times more likely to deliver at HFs than women who have no ability to get to HFs with SDA nearto their residents (AOR, 95\% CI $=13.37,5.9-29.85$ ). This result is concordant with a study done on maternal health care utilizations in Holeta town and a study done in pastoral societies of the Afar region. ${ }^{8,9}$

Moreover, this study indicates that women whose husbands had primary-level education are almost six times more likely to deliver at HFs than women whose husbands are preliterate (AOR, 95\% CI =5.83, 2.03-16.73). This finding is in line with the result from Munisa woreda of southeast Ethiopia. This shows the role of formal health education in influencing the demand and need of utilization of health care facilities. ${ }^{10}$

This study also showed that women's ANC attendances had a significant difference between women who had intended to deliver at HFs and those who intended to deliver at home. Women who attended ANC were two times more likely to deliver at HFs than women who did not attend ANC (AOR, 95\% CI =2.3, 1.07-4.96).

\section{Conclusion}

The major determinants of institutional delivery were feeling healthy, lack of knowledge, long waiting time, poor quality services, cultural beliefs, religious misconception, partner decision, and long travel. According to the FGDs, some women did not prefer institutional delivery due to cultural misconception on the exposure of private parts to a male midwife as their husbands will be unhappy. Almost all discussants agreed that home delivery is a long-held perception and a tradition that has been around for a long period of time. Hence, the community believes that home delivery is better than at a health institution.

\section{Recommendations}

Somali Regional State Health Bureau and other health care providers should work on behavioral change communication and health information in the study area regarding the importance of institutional delivery and ANC follow-up. The Ministry of Health and Regional Health Bureau should improve the accessibility and availability of service-providing organizations, such as hospitals and health centers. The existing misconceptions should be removed by extensive awareness creation workshops and discussions. Traditional birth attendants whom the community trust should be trained to link delivery with nearby health institutions.

It is important to evolve an appropriate institutional framework at a regional and national level to facilitate the implementation of quality health services that promote accessibility of institutional delivery at all levels. Women should be empowered to actively involve in community affairs and decision-making about matters that concern them, including the ability to choose the place of delivery without pleasing or the approval of their husbands. Emphasis should be given in influencing maternal education and husband and relative decisions. The health professionals should be equipped and trained on interpersonal and communication skills and ethics.

All the communities, including teachers, elders, religious leaders, and concerned stakeholders, should carry the mobilization activities on home-to-home bases. Policy makers and health care planners should recognize the importance of institutional delivery and work on improving the situation on the ground level.

\section{Acknowledgments}

This study was funded by CCM. The authors especially appreciated the support and ideas of Somali Regional State Health Bureau, Liben Zone Filtu Woreda Health Bureau, and Filtu Hospital for relevant and valuable data they provided. The authors also thank the Social Welfare and Development staffs in Liben Zone field office for their valuable contribution in organizing and collecting the data and FGD. The authors are also delighted to acknowledge the study participants, data collectors, and supervisors. Last, but not the least, the authors believe that this is the time to pay tribute to their colleagues at Jigjiga University and Samara University who have always been beside us in all endeavors.

\section{Author contributions}

NB and AT contributed to the design of the study and interpretation. AT performed the data analysis and drafted the article. NB critically revised the draft article. NB and AT read and approved the final article. All authors contributed toward data analysis, drafting and critically revising the paper, gave final approval of the version to be published, and agree to be accountable for all aspects of the work.

\section{Disclosure}

The authors report no conflicts of interest in this work.

\section{References}

1. CSA, ICF International. Ethiopia Demographic Health Survey 2011. Calverton, MD: Central Statistical Agency and ICF International; 2012.

2. Ochako R, Fotso J, Ikamari L, Khasakhala A. Utilization of maternal health services among young women in Kenya. BMC Pregnancy Childbirth. 2011;11:1. 
3. Biza N, Mohammed H. Pastoralism and antenatal care service utilization in Dubti District, Afar, Ethiopia, 2015: a cross-sectional study. Pastoralism. 2016;6:15.

4. Central Statistical Agency [Ethiopia]. Ethiopia Mini Demographic and Health Survey 2014. Addis Ababa: Central Statistical Agency; 2014.

5. HSTP the Federal Democratic Republic of Ethiopia, Ministry of Health Sector Transformation Plan 2008-2012 EFY (2015/16-2019/20).

6. CSA. Summary and Statistical Report of the 2007 Population and Housing Census Results. Federal Democratic Republic of Ethiopia Population Census omission. Addis Ababa: CSA; 2008.

7. Worku A, Yalew A, Afework MF. Factors affecting utilization of skilled maternal care in Northwest Ethiopia: a multilevel analysis. BMC Int Health Hum Rights. 2013;13:20.
8. Kidist B, Yohannes D, Desalegn W. Determinants of maternal health care utilization in Holeta town, central Ethiopia. BMC Health Serv Res. 2013; 13:256.

9. Medhanit G, Kassahun N, Jemal Y, Muluken M. Determinants of delivery practices among Afar pastoralists of Ethiopia. Pan Afr Med J. 2012; 13(suppl 1):17.

10. Amano A, Gebeyehu A, Birhanu Z. Institutional delivery service utilization in Munisa Woreda, South East Ethiopia: a community based cross-sectional study. BMC Pregnancy Childbirth. 2012;12:105.

International Journal of Women's Health

\section{Dovepress}

\section{Publish your work in this journal}

The International Journal of Women's Health is an international, peerreviewed open-access journal publishing original research, reports, editorials, reviews and commentaries on all aspects of women's healthcare including gynecology, obstetrics, and breast cancer. The manuscript management system is completely online and includes a very quick and fair peer-review system, which is all easy to use. Visit http://www.dovepress.com/testimonials.php to read real quotes from published authors.

Submit your manuscript here: http://www.dovepress.com/international-journal-of-womens-health-journal 